\title{
Pharmacovigilance in Cabo Verde: Measuring the Impact of Pharmacovigilance Educational Campaign on Consumer's Knowledge
}

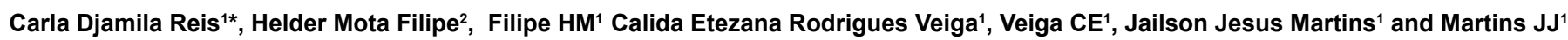

${ }^{1}$ Agência de Regulação e Supervisão de Produtos Farmacêuticos e Alimentares (ARFA), Cape Verde

${ }^{2}$ Faculdade de Farmácia da Universidade de Lisboa, Cape Verde

\begin{abstract}
Background: A monitoring system of adverse drug reactions is vital to patient safety and patients should have an active role in it. However, encouraging consumer involvement in their healthcare requires that they are or can be sufficiently well informed to make rational decisions. Therefore, mass education campaigns can be important to promote public education about medicines.

Purpose: To assess the impact of an educational campaign to promote knowledge of consumer regarding use of medicines.

Methods: A descriptive study was performed for consumer's knowledge regarding rational use of medicine after a TV/radio campaign. A questionnaire was applied during 1 week (from 16 to 23 November 2015) in all urban areas of the capital of Cabo Verde to a population of 73,343. The data were analyzed using descriptive statistics and T-test.

Results: The result reveals a general improvement on knowledge of consumer $(p<0.0001)$ after the TV/radio educational program. For the two most sensitive issue of the first study, the results indicate an improvement of 0.7 percentage points for medicine-risk perception and an increase of 11.6 percentage points for the perception of quality of generics.

Conclusion: Educational campaigns for consumer on the appropriate use of medicines are of crucial importance and well-tailored campaigns can improve the general knowledge, especially by addressing the campaign through the healthcare professional. It is recommended to continue the transmission and amplification of the TV/radio program.
\end{abstract}

Keywords: Rational use of medicine; Pharmacovigilance; Cabo Verde; Consumers; Mass campaigns; Educational program

\section{Background}

A monitoring system of adverse drug reactions (ADRs) is vital to patient safety and patients should have an active role on it. However, encouraging for consumer involvement in their healthcare requires that they are or can be sufficiently well informed to make rational decisions.

The rational use of drugs has received increased attention in the last decade, and as defined by the World Health Organization (WHO), means "any situation where the patients receive medications appropriate to their clinical needs, in doses that meet their own individual requirements, for an adequate period of time, and at the lowest cost to them and their community [1]".

Situation of irrational use such overuse of antibiotics, choice of more expensive drugs and inappropriate self-medication have contribute to increase severe consequences of drug use such ADR, drug resistance and even death. According to the WHO 50\% of patients fail to take their medicines adequately [2]. Therefore, the irrational use of medicine reveals a crosscutting healthcare problem for which any improvement would have important financial and health benefits.

The existing core components defined by the WHO about promoting rational use of medicines, include encouraging countries to mandate a multidisciplinary national body to coordinate medicine use policies, preparing an essential medicines list, establishing clinical guidelines and public education about medicines [3,4].

In Cabo Verde, despite the good health indicators, the first study conducted showed that consumers still have lack of knowledge in some critical aspects such as the perception of medicine-risk $(29.3 \%$ were not aware of medicine risks), quality of generics (not clear for $78.3 \%$ ) and national pharmacovigilance system (only $35.2 \%$ knew they can report), essential aspects of the rational use of medicine [5]. As consequence, awareness campaigns were conducted to promote public education about medicines. After the above mentioned study, the objective of this study was to assess the impact of the educational program on the knowledge of consumers.

\section{Methods}

The study was conducted after an educational campaign entitled "Responsible Medication". The TV/radio program included 10 episodes, with two episodes per week during one month and replacement of each episode during the weekend.

The awareness campaign aimed to (1) inform the public about general concepts regarding medicines (2) alert the consumers about the risks of self-medication; (3) inform the consumers about generic medicines; (4) alert the population about the risk associated with the purchase of medicines on illegal market; and (5) sensitize the consumers to report ADR and drug-related problems.

*Corresponding author: Carla Djamila Reis, Master in Pharmaceutical Regulation Agência de Regulação e Supervisao de Produtos, Farmacêuticos e Alimentares (ARFA), Praia, Cape Verde, Tel: 23826264 10; E-mail: djamila.reis@arfa.gov.cv

Received: April 30, 2016; Accepted July 22, 2016; Published August 02, 2016

Citation: Reis CD, Filipe HM, Filipe HM, Veiga CER, Veiga CE, et al. (2016) Pharmacovigilance in Cabo Verde: Measuring the Impact of Pharmacovigilance Educational Campaign on Consumer's Knowledge. J Pharmacovigil 4: 217. doi:10.4172/2329-6887.1000217

Copyright: @ 2016 Reis CD, et al. This is an open-access article distributed under the terms of the Creative Commons Attribution License, which permits unrestricted use, distribution, and reproduction in any medium, provided the original author and source are credited. 
Citation: Reis CD, Filipe HM, Filipe HM, Veiga CER, Veiga CE, et al. (2016) Pharmacovigilance in Cabo Verde: Measuring the Impact of Pharmacovigilance Educational Campaign on Consumer's Knowledge. J Pharmacovigil 4: 217. doi:10.4172/2329-6887.1000217

Page 2 of 3

The questionnaire was identical to the first study done prior to the campaign and intended to assess the interest and impact of the campaign. The questionnaire was two pages long and divided into the following sections: (1) demographics (age, sex, marital status, school level, income and working status); (2) questions related to knowledge and attitudes regarding rational use of medicine and (3) audience/ performance of the TV/radio program.

The questionnaire was applied during 1 week (from 16 to 23 November 2015) in urban areas of the capital of Cabo Verde (Praia) which is the country largest population center $(28 \%$ of the total weight of the population). The target population included individuals resident in Praia aged greater than or equal to 18 years.

The variation on the knowledge was calculated by the difference between the correct answer in this second study (B) and the correct answer in the first study (A) applied before the campaign. Descriptive analysis and T-test for mean proportion were performed with $95 \%$ confidence level to assess the impact of the educational TV/radio campaign on general knowledge about medicine.

\section{Results}

The population that responded to the questionnaire is similar to the first study. The mean age was 38.89 years ( 37.8 for the first study) and most of the respondents were female $(52.2 \%$ in this study and $51.2 \%$ for the first one). About $45.9 \%$ of respondents have a corresponding level of education to the high school ( $44.1 \%$ in the first study).

In terms of economic characterization, about $41.2 \%$ of the respondents work and $29 \%$ of respondents are unemployed $(47.6 \%$ and $25 \%$ respectively for the first study). With regard to family income, $24.9 \%$ of those interviewed has a household income between 90 to 272 euros $(23.7 \%$ in the first study) and family income less than 90 euros represented $15.1 \%$ in the first study and was $10.5 \%$ in the present study.

In terms of general knowledge, the benefit of medicine was recognized by $88.4 \%$ of the respondents, which represent an increase of $1.1 \%$ compared with the first study that identified $87.3 \%$. The perception that medicine can have risk had a slight improvement of $0.7 \%$ when compared with the first study.

The knowledge that generic medicine can have as good quality as a brand medicine have increased $11.6 \%$ among the respondents, with $33.3 \%$ believing that generic medicine can be as good as brand medicines against the $21.7 \%$ observed in the first study.

In relation to the national pharmacovigilance system, there was an increase of $8.7 \%$ among the respondents that recognized the concept of an ADR. The knowledge that they can report increased $14.2 \%$ among the respondents. The table 1 shows the impact of TV/radio educational program on knowledge of consumers.

\section{Discussion}

This second study aimed to describe the impact of an educational campaign on the knowledge of the consumers regarding the rational use of medicine.

In terms of general knowledge, a T-test for mean proportion were used to assess the impact and revealed a general improvement on knowledge of consumer $(\mathrm{p}<0.0001)$ after the TV/radio educational program. Considering the two most sensitive issues highlighted in

\begin{tabular}{|c|c|c|c|c|c|c|c|}
\hline \multirow{3}{*}{$\begin{array}{l}\text { Knowledge of consumers regarding the } \\
\text { rational use of medicine }\end{array}$} & \multicolumn{3}{|c|}{ First study (A) } & \multicolumn{3}{|c|}{ Second study (B) } & \multirow{2}{*}{$\begin{array}{c}\text { Variation } \\
\text { Corret answer B } \\
\text { Corret answer A }\end{array}$} \\
\hline & TRUE & FALSE & NS/NR & TRUE & FALSE & NS/NR & \\
\hline & Row N \% & Row N \% & Row N \% & Row N \% & Row N \% & Row N \% & Row N \% \\
\hline Medicines used to treat and cure diseases & $87.3 \%$ & $9.2 \%$ & $3.5 \%$ & $88.4 \%$ & $8.9 \%$ & $2.7 \%$ & $1.1 \%$ \\
\hline All medicines are $100 \%$ safe & $29.3 \%$ & $63.5 \%$ & $7.2 \%$ & $27.7 \%$ & $64.2 \%$ & $8.1 \%$ & $0.7 \%$ \\
\hline $\begin{array}{l}\text { Use medicines correctly. allows you to } \\
\text { increase the benefits and limit the risks }\end{array}$ & $93.1 \%$ & $3.9 \%$ & $3.1 \%$ & $95.2 \%$ & $3.5 \%$ & $1.3 \%$ & $2.1 \%$ \\
\hline $\begin{array}{l}\text { Visit a physician before taking a medicine is } \\
\text { a responsible way to take care of your health }\end{array}$ & $97.0 \%$ & $2.3 \%$ & $0.6 \%$ & $98.0 \%$ & $1.9 \%$ & $.2 \%$ & $0.9 \%$ \\
\hline $\begin{array}{l}\text { Follow the indications. amount and duration of } \\
\text { treatment recommended by your physician is } \\
\text { a correct way to use the medicine }\end{array}$ & $97.6 \%$ & $1.7 \%$ & $0.7 \%$ & $97.4 \%$ & $2.1 \%$ & $.5 \%$ & $-0.2 \%$ \\
\hline $\begin{array}{l}\text { A medicine prescribed for you is always } \\
\text { appropriate for another person }\end{array}$ & $8.6 \%$ & $88.0 \%$ & $3.4 \%$ & $13.7 \%$ & $84.4 \%$ & $2.0 \%$ & $-3.6 \%$ \\
\hline $\begin{array}{l}\text { Medicines purchased outside pharmacies } \\
\text { may be fake or of low quality. }\end{array}$ & $81.0 \%$ & $13.1 \%$ & $5.9 \%$ & $88.7 \%$ & $8.2 \%$ & $3.1 \%$ & $7.7 \%$ \\
\hline $\begin{array}{l}\text { In Cape Verde. the sale of medicines outside } \\
\text { pharmacies is prohibited by law }\end{array}$ & $75.6 \%$ & $11.4 \%$ & $13.0 \%$ & $81.5 \%$ & $8.6 \%$ & $9.8 \%$ & $5.9 \%$ \\
\hline $\begin{array}{l}\text { Before being marketed every medicine must } \\
\text { demonstrate that it is efficacious. safe and } \\
\text { with quality. }\end{array}$ & $89.0 \%$ & $3.0 \%$ & $8.1 \%$ & $92.7 \%$ & $3.4 \%$ & $3.9 \%$ & $3.7 \%$ \\
\hline $\begin{array}{l}\text { Generics medicines provide the same } \\
\text { guarantee for my health as branded medicines }\end{array}$ & $21.7 \%$ & $15.4 \%$ & $62.9 \%$ & $33.3 \%$ & $13.9 \%$ & $52.8 \%$ & $11.6 \%$ \\
\hline $\begin{array}{l}\text { Places exposed to light. heat and / or moisture } \\
\text { are the best places to keep medicines }\end{array}$ & $8.6 \%$ & $85.8 \%$ & $5.5 \%$ & $11.4 \%$ & $83.3 \%$ & $5.2 \%$ & $-2.5 \%$ \\
\hline $\begin{array}{l}\text { Check expiry date and the packaging condition } \\
\text { of medicine before buying is important to } \\
\text { ensure a safer use. }\end{array}$ & $95.9 \%$ & $2.8 \%$ & $1.2 \%$ & $97.0 \%$ & $2.5 \%$ & $.5 \%$ & $1.0 \%$ \\
\hline $\begin{array}{l}\text { An adverse reaction is a symptom or side } \\
\text { effect caused by a medicament. }\end{array}$ & $67.5 \%$ & $9.5 \%$ & $23.0 \%$ & $76.2 \%$ & $8.8 \%$ & $15.0 \%$ & $8.7 \%$ \\
\hline $\begin{array}{l}\text { The reporting of adverse reactions helps to } \\
\text { ensure that medicines are safer in Cape Verde }\end{array}$ & $75.1 \%$ & $5.3 \%$ & $19.6 \%$ & $89.3 \%$ & $3.9 \%$ & $6.8 \%$ & $14.2 \%$ \\
\hline
\end{tabular}

Table 1: Knowledge of consumers regarding the rational use of medicine. 
Citation: Reis CD, Filipe HM, Filipe HM, Veiga CER, Veiga CE, et al. (2016) Pharmacovigilance in Cabo Verde: Measuring the Impact of Pharmacovigilance Educational Campaign on Consumer's Knowledge. J Pharmacovigil 4: 217. doi:10.4172/2329-6887.1000217

Page 3 of 3

the first study, medicine-risk perception and quality of generics, the results indicate an improvement of 0.7 and $11.6 \%$, respectively. For those same concepts, it is also relevant to verify that the wrong responses have decreased $1.6 \%$ regarding medicine risk and $1.5 \%$ for quality of generics.

It is important to refer that knowledge regarding the ADR concept and national notification systems were improved but the $\%$ of wrong answers proves that there is an impressive need for improvement.

Although there was a good decrease in the \% of "Don't know" responses, the existing level demonstrated there is a need for continued information campaigns to allow a bigger impact on knowledge and to achieve changes in attitude.

Therefore, as stated in the first article, the relevance of these results for countries as Cabo Verde is to identify priorities for a successful health policy whose interventions could increase therapeutic adherence and prevent medicine resistance. As showed in a previous study, approximately $25 \%$ of the Cape Verdean population acquires medicine outside de legal market which demonstrates clearly that risk and quality of medicine are not yet perceived by the population as a concern [6].

According to other study, addressing quality and safety of medicines through healthcare professionals, to include consumers with information campaigns may be an adequate strategy to reinforce the promotion of rational use of medicines done through healthcare professionals [7].

One of the drawbacks was the impossibility to interview the exact same persons of the first study, which may limit the results interpretation. For better comparability between specific issues related to rational use of medicine paired sample would be more advised.

\section{Conclusion}

Educational campaigns for consumer on the appropriate use of medicines are of crucial importance and well-tailored campaigns can improve the general knowledge, especially by addressing the campaign through the healthcare professional. The educational activities should be focused on lower level of education and income groups where medicine use patterns are in most need of change.

It is recommended to continue the transmission and amplification of the TV/radio program particularly in schools. Consequently, it is important to plan, develop, implement, monitor, evaluate and reassess effective consumer education programs on knowledge and attitude change regarding rational use of medicine.

\section{References}

1. World Health Organization (1985) The Rational Use of Drugs: Report of the Conference of Experts, Nairobi.

2. World Health Organization (2010) Medicines: rational use of medicines.

3. le Grand A, Hogerzeil HV, Haaijer-Ruskamp FM (1999) Intervention research in rational use of drugs: a review. Health Policy Plan 14: 89-102.

4. World Health Organization (2002) Promoting rational use of medicines: core components-WHO Policy Perspectives on Medicine.

5. Reis CD, Veiga CE, Martins JJ (2016) Pharmacovigilance in Cabo Verde: Measuring the Awareness and Knowledge of Consumers. J Pharmacovigil 4:200.

6. Reis CD, Tavares EJ (2015) Illegal Market of Medicines in Cabo Verde: Characterization for Action. J Pharmacovigil 3: 178.

7. Alrasheedy AA, Mohamed AH, Stewart K, Kong DCM, Aljadhey $\mathrm{H}$, et al (2014) Patient knowledge, perceptions, and acceptance of generic medicines: a comprehensive review of the current literature. Patient Intelligence 6: 1-29. 